\title{
RAPID TURNOVER OF Plasmodium falciparum VAR GENE TRANSCRIPTS AND GENOTYPES DURING NATURAL NON-SYMPTOMATIC INFECTIONS
}

\begin{abstract}
SUMMARY
The var genes of Plasmodium falciparum code for the antigenically variant erythrocyte membrane proteins 1 (PfEMP1), a major factor for cytoadherence and immune escape of the parasite. Herein, we analyzed the var gene transcript turnover in two ongoing, non-symptomatic infections at sequential time points during two weeks. The number of different circulating genomes was estimated by microsatellite analyses. In both infections, we observed a rapid turnover of plasmodial genotypes and var transcripts. The rapidly changing repertoire of var transcripts could have been caused either by swift elimination of circulating var-transcribing parasites stemming from different or identical genetic backgrounds, or by accelerated switching of var gene transcription itself.
\end{abstract}

KEYWORDS: Plasmodium falciparum; Switching; Antigenic variation; PfEMP1.

\section{INTRODUCTION}

Insufficiently treated infections with the apicomplexan parasite Plasmodium falciparum can develop into long lasting and symptomfree infections, depending on the immunocompetence of the host ${ }^{30}$. In order to escape the constant attack of the host immune system the parasite employs antigenic variation and the $P$. falciparum erythrocyte membrane protein 1 (PfEMP1, ${ }^{19}$ ) family of proteins was described as a major factor of virulence and also target of the host immune response and variant specific immunity ${ }^{9}$. Importantly, semi-immune African adults showed higher anti-PfEMP1 titers than non-immune children ${ }^{21}$. The PfEMP1s are encoded by a large gene family - termed var - and it is believed that every parasite genome contains 40-50 var genes ${ }^{6}$. Possibly in order to coordinate most effectively the antigenic repertoire of its genome, the expression of var genes is tightly controlled. It was shown that var transcription is relaxed in ring stage parasites, where almost all var genes present in the genome are transcribed. However, only one or a few transcripts are found in the trophozoite stages (allelic exclusion), which are then translated to PfEMP1 polypeptides which itself are transported to the surface of the corresponding trophozoiteinfected red blood cells ${ }^{10,27}$. Recently, a conserved var transcript, which seems not to be translated was detected in mature stages of a number of different isolates ${ }^{18}$. The intrinsic switching rate of var gene transcription, defined as the rate to which the expression of one PfEMP1 switches to another, was shown to occur at a rate of $2.4 \%$ per generation in vitro, indicating that the half of a previously monomorphic population of $P$. falciparum parasites would, after 30 generations or 60 days, still express the same PfEMP $1^{24}$. Additionally, by computer-aided modeling it was calculated that one antigenic phenotype would not last longer than two weeks until the onset of an efficient $\operatorname{IgG}$ response ${ }^{22}$. As detectable antiPfEMP1-immunoglobulins are present in individuals frequently exposed to $P$. falciparum ${ }^{9}$, it seems unlikely for a circulating parasite population to maintain the expression of the same PfEMP1 for an extended period such as 60 days. Indeed, a recently published report showed that var switching may be faster than $16 \%$ per generation in the early phase of blood stage infection ${ }^{23}$. However, this study only considered the initial stages of infection in non-immune persons and not the more common field situation of partial immunity and high immune pressure. Also, no follow-up of var gene transcription of individual infections was done. Another study by KAESTLI et al. showed the occurrence of changing var transcripts in semi-immune children but the underlying genotypes were identified only on the base of one single polymorphic marker and in longer time intervals ${ }^{15}$. Herein, we studied the longitudinal change of var transcripts and circulating plasmodial genomes by RT-PCR and microsatellite marker analysis in two untreated non-symptomatic patients during short time intervals.

\section{MATERIALS AND METHODS}

Patients and blood samples: In July 2001, two citizens, one male (20 years old) and one female (43 years old) of the Candelária suburb of Porto Velho, Rondônia, Brazil, participated in this study. They presented a non-symptomatic $P$. falciparum infection diagnosed by PCR during a larger active surveillance effort performed in the whole village. Both gave their written consent before participating in the study and ethical clearance was obtained from the local federal commission

Financial support: CNPq, and Fapesp grant 00/11136-0 (G.W.). F.P.A. and U.G. were supported by doctoral fellowship grants (Fapesp).

(1) Departamento de Parasitologia, Instituto de Ciências Biomédicas 2, Universidade de São Paulo, Av. Prof. Lineu Prestes, 1374, 05508-900 São Paulo, SP, Brasil.

(2) Centro de Pesquisas em Medicina Tropical, BR 364, km 4.5, 78970-900 Porto Velho, RO, Brasil.

Correspondence to: Gerhard Wunderlich, Fax +55-11-30917417, email: gwunder@usp.br 


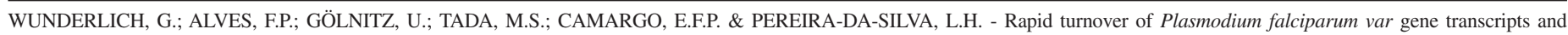
genotypes during natural non-symptomatic infections. Rev. Inst. Med. trop. S. Paulo, 47(4):195-201, 2005.

for experiments involving humans. Both individuals lived and worked at $50 \mathrm{~m}$ distance to each other several months before and during the trial.

Five blood samples of $8 \mathrm{~mL}$ were taken in 3-day intervals from each patient and transferred into heparinized tubes. A thin blood smear was prepared. The blood was then centrifuged and plasma and buffy coat were stored at $-20{ }^{\circ} \mathrm{C}$. The remaining erythrocytes were washed three times in serum free RPMI 1640 medium and $3 \mathrm{~mL}$ of packed RBC were then incubated under $90 \% \mathrm{~N}_{2}, 5 \% \mathrm{O}_{2}, 5 \% \mathrm{CO}_{2}$ for $12-14 \mathrm{~h}$ in $10 \%$ AB-serum supplemented RPMI 1640 medium at a hematocrit of $20 \%$. After incubation, trophozoite stage parasites were purified by gelatin-floating ${ }^{28}$. Parasite counts were determined by reading Giemsastained blood smears. We found very low parasitemias ( $\sim 50$ parasites/ $\mu \mathrm{L}$ ) and only sporadically single gametocytes could be identified at any time point of infection.

Preparation of parasite RNA and genomic DNA: The purified trophozoite-infected red blood cells, resuspended in $250 \mu \mathrm{L}$ PBS, were lysed with $750 \mu \mathrm{L}$ Trizol LS (Life Technologies). RNA was then extracted as described by the manufacturer, with the modification that the isopropanol precipitation was done for one $\mathrm{h}$ on ice and the centrifugation of the precipitate was for one $\mathrm{h}$ at $12,000 \mathrm{~g}$ at $4{ }^{\circ} \mathrm{C}$. The final RNA pellet was dissolved in $7 \mu \mathrm{L}$ of ultrapure water and immediately used for DNAse 1 digestion and cDNA-synthesis. Genomic DNA (gDNA) was purified from the buffy coat fraction as described $^{28}$. Briefly, the buffy coat fraction was centrifuged for five min at $8000 \mathrm{~g}, 4{ }^{\circ} \mathrm{C}$, and the resulting pellet was saponin-lysed $(0.1 \%$ in PBS) for five min at room temperature (RT). Afterwards, $2 \mathrm{x}$ concentrated SDS-lysis buffer and Proteinase K (Life technologies) to a final concentration of $0.1 \mathrm{mg} / \mathrm{mL}$ was added, and the mixture was incubated for four $\mathrm{h}$ at $56{ }^{\circ} \mathrm{C}$. After sequential phenol, phenol/ chloroform, and chloroform extractions, the genomic DNA was precipitated by addition of two volumes ethanol, left for one $\mathrm{h}$ on ice and then centrifuged for $10 \mathrm{~min}$ at $12,000 \mathrm{~g}$ and $4{ }^{\circ} \mathrm{C}$. Each gDNA sample was resuspended in $50 \mu \mathrm{TE}$ and stored at $-20{ }^{\circ} \mathrm{C}$ until use.

Reverse transcription, PCR and cloning of var transcripts: Each freshly prepared RNA sample was sequentially treated three times for 15 min with DNAse1 (Life Technologies) following the manufacturer's protocols. The final volume of the DNAse1 reaction was $22 \mu \mathrm{L}$. Four $\mu \mathrm{L}$ of this DNA-free RNA solution was then submitted to reverse transcription. The reaction was carried out following the manufacturer's instructions using two var specific oligonucleotides as described previously ${ }^{1}$. One $\mu \mathrm{L}$ of the resulting cDNA was then used as template for a PCR which employed var-DBL $\alpha$ specific, degenerated oligonucleotides (sense: 5'-GCCTGYGCKCCATWYAGRCG-3', antisense: 5'-CCWATRCYGCAAAACTKCGTG-3', (sequences from reference ${ }^{13}$ and ${ }^{17}$, respectively) termed alternative var oligonucleotides, $\mathrm{AV}$ ). For the detection of primer bias, $100 \mathrm{ng}$ of genomic DNA was used as template for amplification. The previously published universal var oligonucleotides ${ }^{31}$ were also tested. The amplification conditions were: $94{ }^{\circ} \mathrm{C}$, one $\min , 53{ }^{\circ} \mathrm{C}$, one min and $65{ }^{\circ} \mathrm{C}, 1.5 \mathrm{~min}$, over 35 cycles followed by $10 \mathrm{~min}$ at $65^{\circ} \mathrm{C}$ for the $\mathrm{AV}$ oligonucleotides, or $94{ }^{\circ} \mathrm{C}$, one min, $42{ }^{\circ} \mathrm{C}$, one min, $60{ }^{\circ} \mathrm{C}$, one min over 35 cycles for the universal var oligonucleotides, including the use of Platinum Taq polymerase (Life Technologies), instead of conventional Taq polymerase. After TAE-agarose gel analysis, the corresponding 200 -
220 nt-bands (350 - $400 \mathrm{nt}$ for universal var oligonucleotides) were excised and purified using the glassmilk technique ${ }^{33}$. Purified DNA fragments were then ligated in the pGEM-T easy vector (Promega) and transformed in competent $E$. coli $\mathrm{DH} 5 \alpha$ cells. Of each amplificate, 20 recombinant clones were prepared and sequenced in an ALF2 automatic sequencer using Cy5-labeled SP6 and T7-promoter oligonucleotides in combination with the Thermosequenase sequencing kit (Amersham-Pharmacia) following the manufacturer's instructions.

Plasmodium culture and selection of adhesive phenotypes: The culture of $P$. falciparum 3D7 parasites was conducted as described earlier ${ }^{32}$. Selection of 3D7 parasites for cytoadhesion on Chinese hamster ovary cells stably transfected with the human E-selectin gene ${ }^{8}$ was done for five cycles as described ${ }^{28}$. The synchronization of ring stage parasites was done by sorbitol lysis ${ }^{28}$.

Plasmodium species diagnosis and microsatellite genotyping: The gDNA samples were tested for the presence of $P$. falciparum and $P$. vivax. For this purpose, diagnostic PCRs using species-specific oligonucleotides for either $P$. vivax or $P$. falciparum ribosomal RNA genes, were performed exactly as described ${ }^{29}$. Eleven microsatellite markers were amplified from gDNAs using published oligonucleotides in PCRs, exactly as described previously ${ }^{4}$. Microsatellite products were analyzed on the ALF2 automatic sequencer using commercial weight standards (Amersham-Pharmacia) and evaluated using the Allele Links 1.0 software package (Amersham-Pharmacia). Mixed infections were considered when a secondary peak of at least $33 \%$ intensity of the main peak was observed.

\section{RESULTS}

Two patients remained infected during two weeks with only $\boldsymbol{P}$. falciparum: In order to determine if the individuals participating in our trial were found naturally infected with only P. falciparum parasites, nested diagnostic PCRs were performed as described ${ }^{29}$. Only $P$. falciparum, but not $P$. vivax or $P$. malariae genomic DNA could be detected in all of the tested samples, indicating that the individuals were solely infected with $P$. falciparum throughout the test period (data not shown).

Rapid fluctuation of different genomes during infection: The combined use of several microsatellite markers can efficiently detect the presence of different circulating genomes. ANDERSON et al. described a set of 12 markers, which detect with high confidence the presence of different $P$. falciparum genomes in a sample ${ }^{4}$. Using 11 of these markers, the ten gDNAs, resulting from five samples of each of the two patients, were analyzed. As described in Table 1, individual \#1 was infected during the first three time points with apparently only one clonal parasite population. On the days 10 and 13, however, in two (day 10) or four markers (day 13) additional signals appeared which indicated the presence of at least one additional different genotype. The genotype present in samples from days one to seven seemed to persist throughout the test period. A more disperse microsatellite pattern was observed in individual \#2: whereas on day one and four at least two genotypes were present, other genotypes appeared on day seven (markers Poly- $\alpha$, PfPK2, Taa87 and Taa109) which seemed to disappear rapidly on day 10 and 13 , resulting in one of the initial genotypes of day one. On day seven and 10 individual \#2 showed a short-lived switch 


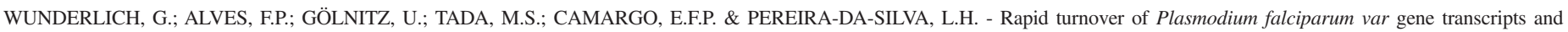
genotypes during natural non-symptomatic infections. Rev. Inst. Med. trop. S. Paulo, 47(4):195-201, 2005.

Table 1

Microsatellite analysis of two non-symptomatic infections during a two-week interval

\begin{tabular}{|c|c|c|c|c|c|c|c|c|c|c|}
\hline \multirow[b]{2}{*}{ Marker } & \multicolumn{5}{|c|}{ Individual 1} & \multicolumn{5}{|c|}{ Individual 2} \\
\hline & day 1 & day 4 & day 7 & day 10 & day 13 & day 1 & day 4 & day 7 & day 10 & day 13 \\
\hline Ta1 & 177 & 177 & 177 & 177 & 177 & 177 & 177 & 177 & 183 & 183 \\
\hline Poly- $\alpha$ & 151 & 151 & 151 & 151 & 151 & 190 & 190 & 151,190 & 190 & 190 \\
\hline Taa60 & 72 & 72 & 72 & 72 & 72 & 72 & 72 & 72 & nd & 72 \\
\hline ARA2 & 66 & 66 & 66 & 66 & 66 & 66 & 66 & 66 & 66 & 66 \\
\hline Pfg377 & 95 & 95 & 95 & 95 & 95,98 & 95 & 95 & 95 & 95 & 95 \\
\hline PfPK2 & 174 & 174 & 174 & 174,168 & 174,168 & 168 & 168 & 168,174 & 168 & 168 \\
\hline Taa87 & 96 & 96 & 96 & 96 & 96 & 96 & 96 & 96,111 & nd & 96 \\
\hline Taa109 & 163 & 163 & 163 & 163 & 163 & 163 & 163 & 160,163 & nd & 163 \\
\hline Taa81 & 118 & 118 & 118 & 118,121 & 118,121 & 118,121 & 118,121 & 121 & 121 & 121 \\
\hline Taa42 & 188 & 188 & 188 & 188 & 188,197 & 197,200 & 197,200 & 200 & 200 & 200 \\
\hline 2490 & 84 & 84 & 84 & 93 & 84 & 84 & 84 & 81 & 90 & 84 \\
\hline
\end{tabular}

The microsatellite markers (left row) were as described in ANDERSON et al. ${ }^{4}$. The sizes in bp of the fragment after analysis with the allele links 1.0 software package are shown in rows per isolate. Multiple numbers per cell indicate double bands. The minimum signal intensity for consideration as a positive signal was set to 33\% intensity of the main allele peak. nd means not detectable.

to another haplotype in the microsatellite marker 2490. Analysis of the pherograms revealed that the microsatellite marker size of $84 \mathrm{bp}$ was also present in these samples, although below the established peak intensity cutoff. Some microsatellite markers appeared in identical sizes in both patients (markers Ta1, Taa60, ARA2, Pfg377, Taa87, Taa109, Taa81 and 2490, and punctually Poly- $\alpha$ and Taa42). Some microsatellite markers in this test were found only in one size (Taa60 and ARA2). Individual \#2 samples did not amplify satisfyingly for some markers in the day 10 sample even after increasing or decreasing template amounts (Table 1 and data not shown).

Rapid change of present var transcripts during short time intervals: In the next experiment, we analyzed how many different var transcripts could be found at each time point of the infection. In all but one sample (individual \#2, sample day 10) we were able to obtain a RT-PCR product. After cloning and sequencing of 20 RT-PCR generated fragments for each time point, 180 sequences were obtained. The frequency of which each transcript was found in the analyzed sequences per sample was then plotted against the time point.

As shown in Fig. 1, the relative quantity of transcripts varied per time point. Under the given conditions, up to five different transcripts could be identified. For individual \#1, for example, two main different transcripts were found on time point day one of the trial. One of these transcripts (AF333287) remained present, although perhaps in different quantities, throughout the time points four to 10 , but disappeared completely at the last time point, when virtually only one transcript was present. Individual \#2, even with one time point less, showed similar kinetics of change in the present major transcripts. Accordingly, transcripts of type AF172777 were present at all time points except on day 13 where they disappeared. Another transcript, AF333287, was present in all four time points. Interestingly, the two individuals shared a number of common transcript sequences (sequence types AY172777, AF333287, AF172292, AF333294, AF333285).

In order to exclude that the observed changes of transcript sequences reflected the relative quantities of present var transcripts and were not

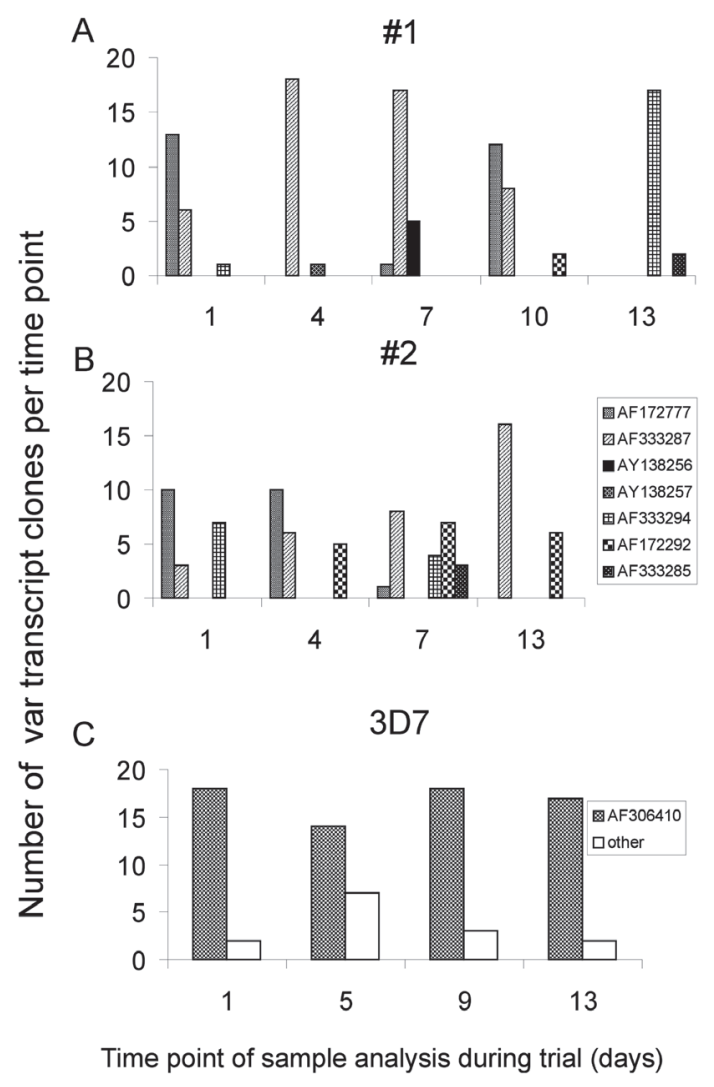

Fig. 1 - Frequency of var transcripts after Reverse transcription and Polymerase chain reaction and cloning in two non-symptomatic infections or in a cytoadherence selected 3D7 culture. A and B: After sequencing, the number of how often each sequence (indicated by its GenBank accession number) was found, was plotted against the time point when the sample was taken. C: Frequency of var transcripts in a selected 3D7 culture plotted against 4 consecutive time points. The samples were taken from a synchronized culture as described in Methods and RT-PCR amplified as the patient samples. To simplify the graph, less abundant transcript sequences, non-AF306410 ("other") were joined in one bar. 


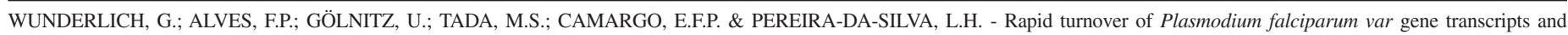
genotypes during natural non-symptomatic infections. Rev. Inst. Med. trop. S. Paulo, 47(4):195-201, 2005.

PCR artifacts, we monitored the transcript turnover in a comparable amount of 3D7 parasites, which were previously selected for E-Selectin adherence and should therefore maintain a certain var transcript (AF306410) during two weeks. To this end, $10^{5}$ and five times cytoadherence-selected and synchronized parasites were sequentially harvested in 4 day-intervals when they were in 18 h-trophozoite stage. After RNA purification, RT-PCR and cloning of the resulting fragments, 20 clones were sequenced per time point. The mainly encountered transcript similar to the sequence AF306410 (corresponding to PlasmoDB gene PFD0995c/PFD1000c) was present in similar clone numbers in all of the tested samples. Several other sequences were observed at all time points. None of these additional sequences were encountered in a consistent fashion throughout the test period as was the sequence AF306410, supporting the view that the observed changes in var transcripts were no artifacts.

\section{DISCUSSION}

The goal of the present study was to elucidate the turnover time of circulating var transcripts during a natural infection with solely $P$. falciparum as infectious agent which may indicate how many PfEMP1 variants are exposed to the host at sequential time points. In order to estimate the number of infecting $P$. falciparum genotypes, we also monitored the polymorphism of 11 different microsatellite markers of the parasite genome at given time points. To our knowledge, this is the first time that microsatellite analysis was used to investigate genotype content in a sequential manner in ongoing infections. The fluctuation of var transcripts was analyzed during two weeks using RT-PCR with a pair of degenerated oligonucleotides amplifying the most dominant var gene transcripts.

By microsatellite analysis, we observed the rapid appearance and disappearance of $P$. falciparum genotypes in rather short time intervals which is in clear accordance with earlier data presented by BRUCE et $a l$. In their study, the fluctuation of different genotypes of $P$. vivax and $P$. falciparum was monitored during a 60 day period in a cohort of 34 school children, based on single copy gene polymorphisms. A rapid turnover of genotypes and also different Plasmodium species was observed. In some cases, the authors detected a rapid fluctuation of genotypes even when only one species was present ${ }^{7}$. In the case of a specific genotype being present for prolonged periods, the authors suggested that antigenic variation in parasites of that genotype might explain its persistence. In the present study, we identified the circulating genotypes at each time point by the use of eleven different microsatellite markers ${ }^{4}$, a method which should result in a rather higher resolution than the analysis of only three polymorphic loci as used by BRUCE et $a l .{ }^{7}$. We found that both examined individuals had multiple circulating genomes at least at two of five time points of infection. Individual \#2 showed at three time points at least two, and at one time point possibly more than two infecting genotypes. The absolute number of circulating different genotypes may be higher if one considers all possible combinations of different microsatellite loci per time point. The turnover of different genotypes in these patients seemed high: Individual \#2 showed only at two sequential time points identical combinations of microsatellites while being infected with at least two genotypes, and on all other days at least one marker was different from the marker of the previous time point. Similar results were also reported in the study from BRUCE et al. ${ }^{7}$. Nevertheless, the small difference between the circulating genotypes in each of the both individuals, expressed as a different marker value in only two to four of eleven loci, is highly suggestive that the circulating strains per individual are indeed very similar. However, the question how many var genes are shared between two genomes when most microsatellite markers are identical remains to be elucidated.

As judged from microsatellite markers, the genotype defined by the microsatellite values observed on day one to seven of the study was present throughout the two week-course of infection in individual \#1. In individual \#2, a shift from one dominant genotype defined by the shift of the Ta1 marker from the allele with 177 to $183 \mathrm{bp}$ and marker Taa42 with the allele sizes 197 shifting to 200 bp could be observed, suggesting the disappearance of the initial parasite population. Importantly, many of the microsatellite marker values were identical in both individuals, suggesting a common genetic origin of the infecting parasites, which could be expected since they live in relative proximity $(50 \mathrm{~m})$ to each other. Recent studies measuring the variation of infecting genotypes at different loci in several malaria-endemic areas pointed out that in Brazil the local variation of genomes expressed as differing microsatellite sizes is very low ${ }^{2,3}$, supporting the herein found low variation between the circulating genotypes. In the day 10 sample of individual \#2, certain microsatellite markers were missed because the quantity of the corresponding circulating genotype may have decreased temporarily below the detection limit, coincident with the failure in var gene transcript detection in this sample.

We then monitored the var gene transcription. We were not able to amplify var transcripts applying the presumably best conditions to obtain unbiased var transcription analysis results ${ }^{31}$. The reason for this may be a lower efficiency of amplification when using the universal oligonucleotides. In field samples from the Brazilian Amazon with higher parasitemia, the universal var oligonucleotides work satisfactorily ${ }^{16}$. In order to evaluate var transcription in our samples, we employed the AV oligonucleotides already used successfully in an earlier study ${ }^{1}$.

In order to confirm the results obtained by the herein used primer combination, two experiments were performed in parallel, which helped to validate the results obtained by analysis of the field samples. First, we showed that the use of var ATS-specific oligonucleotides instead of random oligonucleotides did not lead to a preferential detection of distinct var genes, and random priming before RT led to the same detection of transcripts as var specific ATS-priming (Table 2), using the universal var oligonucleotides in a 3D7 background. A similar ATSprimed RT-approach was also used in the study of KAESTLI et al. ${ }^{15}$. Second, the herein used AV oligonucleotides amplified the same var genes as the universal oligonucleotides. Even minor transcripts were identified with both oligonucleotide pairs (Table 2). Importantly, there is no preferential detection of the AF306410 sequence with the AV oligonucleotide pair when amplifying 3D7 genomic DNA (data not shown).

We also tested the primer bias on a patient gDNA sample and found that a preferential amplification occurred on the var sequence AF333287. Consequently, any accumulated appearance of this sequence must be judged as overestimated (Fig. 2). When we estimated how many different var genes of supposedly 50 different genomic copies 


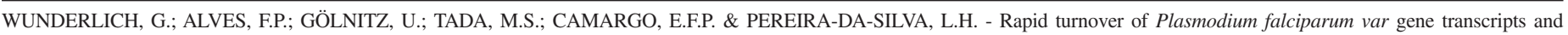
genotypes during natural non-symptomatic infections. Rev. Inst. Med. trop. S. Paulo, 47(4):195-201, 2005.

Table 2

Clone sequence distribution using different oligonucleotides for reverse transcription and polymerase chain reaction

\begin{tabular}{lccc}
\hline & \multicolumn{3}{c}{ Oligonucleotides used for PCR } \\
& $\begin{array}{l}\text { Universal var } \\
\text { oligonucleotides }\end{array}$ & AV \\
& ATS-Mix & Random & ATS-Mix \\
Oligos used for RT & ATS-leotides \\
\hline Sequence AF133867 & 16 & 15 & n.a. \\
Sequence AF306410 & n.a. & n.a. & 16 \\
Other sequences & $4 *$ & $5 *$ & $4 *$ \\
\hline
\end{tabular}

RNA from a 3D7 culture selected for E-selectin cytoadherence was reverse transcribed using random or var specific ATS-oligos and PCR-amplified using universal var oligos or AV oligos as described, cloned and 20 clones were analyzed per sample. n.a. means not applicable. (*) Minor transcripts found in all assays are from PlasmoDB var genes PfD0615C and PfZ94747. AF133867 and AF306410 are located on the same var genes PfD995C and PfD1000C which have identical 5' regions (www.plasmodb.org).
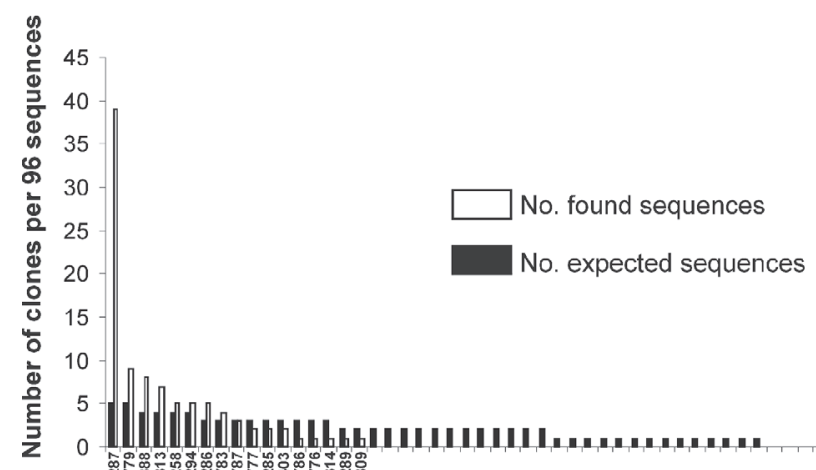

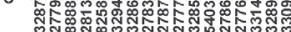

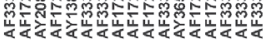

\section{Sequence ID}

Fig. 2 - Testing the individual primer bias: frequency distribution of var sequences amplified from a genomic Plasmodium falciparum DNA sample. The gDNA sample of individual \#1, day 4, was used as a template for PCR, applying identical amplification conditions as in RTPCRs. Products were cloned as described in Methods and 96 clones were sequenced. The number in which each sequence was found is indicated in vertical bars and the GenBank entry of each sequence is shown at the bottom of the $\mathrm{x}$-axis. Black bars indicate the expected sequence frequency distribution (calculated using the BINOMDIST function of MS-Excel ${ }^{31}$ ) and open bars the observed distribution.

were amplified using the AV oligonucleotides, we obtained 17 different sequences out of 96 reads. From the number of reads performed, one would expect to obtain 43 sequences out of 50 possibly present sequences, which indicates that a number of present transcript sequences had probably not been amplified. Nevertheless, the oligonucleotides used herein recognized more sequences than the initially used primer pair ${ }^{17}$, which identified only 12 different sequences in 163 reads from 3D7 genomic $\mathrm{DNA}^{31}$. We also found three transcript sequences that were not amplified from the genomic DNA sample (Sequences AY138256, AY138257, AF172292). Consequently, the frequency to which these three sequences were observed must then be considered underestimated. Altogether, although the herein used primer pair may not be optimal to reflect the absolute transcript quantities, which can only be achieved in a reliable way using a Real-time PCR approach as done by SALANTI et al. ${ }^{25}$, the results of the transcript turnover between samples studied under the same conditions are valid, given that the cytoadherence-selected 3D7 culture showed no transcript variation and the successive patient samples did.

When comparing the genomic data with the data of var transcription at each time point, we observed a small number of circulating var transcript variants. These may, on one hand, reflect the abundance of one genotype expressing one determined PfEMP1 at a given time point, and the expression of minor transcripts var from other subpopulations of the same genotype, as in the case of the day one or day seven sample of individual \#1. Alternatively, on time points when multiple genomes are present, the simultaneous transcription of one var variant from different, but highly similar genomes (compare individual \#1, day 13 transcript sequences) may take place. Again, it must be emphasized that the encountered transcript frequencies cannot be interpreted as absolute values and reflect only bulk differences in the abundance of each transcripts. One must also be aware that less abundant transcripts which are not translated in PfEMP1 may be among the identified transcripts $^{11,20}$, although the herein used methodology may be not as sensitive as the assays used by the other authors who employed either higher sample quantities, nested PCRs, or higher cycle numbers ${ }^{23}$. On the other hand, the chosen time point for RNA preparation (12 h after taking the blood sample, considering 4 h-old ring stage parasites in the peripheral blood) matches exactly the time point when var transcripts are most likely to be translated into protein ${ }^{18,27}$. The socalled sterile var transcript found in trophozoites of many different isolates from Africa ${ }^{34}$ and also Brazilian field isolates ${ }^{1}$, but which is in most cases not translated ${ }^{18}$, was not identified in our samples.

From our data or the data of the study of PETERS et al. ${ }^{23}$, is it possible to deduce the in vivo var gene switching rate of $P$. falciparum, understood as the parasite's molecular switch to activate transcription of one var gene and inactivation of another? The answer is no, since it is impossible to monitor var gene transcription at once in all circulating infected red blood cells. The high var gene transcript turnover observed by the group of PETERS et al. could have been caused by the simple elimination of parasite subpopulations expressing determined PfEMP1s and the more effective expansion of other genetically identical parasites expressing different PfEMP1s. In view of our results describing the rapid turnover of circulating genomes in short time intervals and earlier results of BRUCE et al. ${ }^{7}$, it is highly probable that selective elimination of circulating variants and not accelerated switching was responsible for the fast turnover of var gene transcripts in our work and in the study of PETERS et al. ${ }^{23}$. A conclusive answer to this issue of host factor influence on var gene switching may only be found in in vitro experiments where the growth and elimination of parasites can be monitored.

Another interesting finding of our experiments is that two different individuals were infected with parasite strains that expressed a partially overlapping repertoire of DBL $\alpha$ sequences. Given the high number of different var genes in nature ${ }^{12}$, the chance of finding the same var genes transcribed at any given time point in two different infections should be rather small, even in the presence of biased amplification. On the other hand, in a recent study where var transcripts from symptomatic patients from the same area were analyzed, an overlap of the transcribed var repertoire was also detected, suggesting that the 


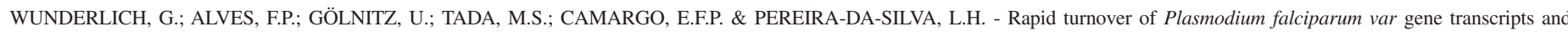
genotypes during natural non-symptomatic infections. Rev. Inst. Med. trop. S. Paulo, 47(4):195-201, 2005.

overall quantity of circulating var genes is indeed limited in that specific area $^{1}$. From a biological point of view, during long-lasting infections only the biologically fittest PfEMP1 variants should persist, and consequently, the herein described sequences may feature a number of members of PfEMP1 molecules with a low immunogenicity and a mostly non-pathologic cytoadherence profile as suggested earlier by SAUL $^{26}$.

A recent study measured the intrinsic off and on rates for determined var transcripts ${ }^{14}$. Certain var genes seem to be switched on and off more rapidly than others and it was hypothesized that upon initial infection, very slowly off-switching var genes dominate. These variants would then rapidly be eliminated through the action of the immune response. In a later chronic stage of infection (the stage when our herein studied samples were taken), rapidly off-switching var genes are believed to prevail ${ }^{14}$. Our data could then also be interpreted that the herein detected var transcripts are part of the group of "fast-off" switching var genes.

In three recent studies, the appearance of distinct var transcripts was associated with severe disease $\mathrm{e}^{5,16}$. Accordingly, the appearance of identical transcripts in non-symptomatic carriers may point to "nonsevere" associated PfEMP1s. For this purpose, the analysis of transcribed var genes, shown in this study to be a feasible task, in numerous non-symptomatic individuals could be conducted to address this issue.

Taken together, our data indicate that during infections with $P$. falciparum, the human host seems to be confronted with a rapidly changing repertoire of antigenic PfEMP1 variants. Further work must be invested to unveil if a direct immune response against expressed PfEMP1 molecules triggers this rapid change of herein identified var transcripts or if other parasite-killing serum factors remove frequently determined PfEMP1-expressing P. falciparum populations.

\section{RESUMO}

\section{Rápida mudança de transcritos var e de génotipos de Plasmodium falciparum em infecções assintomáticas naturalmente adquiridas}

Os genes var de Plasmodium falciparum codificam as proteínas variantes da superfície do eritrócito infectado (PfEMP1). Neste estudo examinamos a mudança de transcritos destes genes var em duas infecções assintomáticas durante um curto prazo e estimamos simultaneamente o número de genomas circulantes nas mesmas amostras por análise de microssatélites. Nas duas infecções observamos uma rápida mudança de genótipos e transcritos de genes var. A mudança acelerada do repertório de transcritos possivelmente foi causada pela rápida eliminação de parasitas circulantes transcrevendo genes var a partir de genomas iguais ou diferentes, ou pela mudança acelerada da própria transcrição (switching) de genes var.

\section{ACKNOWLEDGMENTS}

To W. Fischer for technical assistance in sequencing, Marcelo U Ferreira for helpful discussions, and the medical staff of the CEPEM at the outpost of Candelária. To the Candelária community.

\section{REFERENCES}

1. AFONSO NOGUEIRA, P.; WUNDERLICH, G.; TADA, M.S. et al. - Plasmodium falciparum: analysis of transcribed var gene sequences in natural isolates from the Brazilian Amazon region. Exp. Parasit., 101: 111-120, 2002.

2. ALVES, F.P.; DURLACHER, R.R.; MENEZES, M.J. et al. - High prevalence of asymptomatic Plasmodium vivax and Plasmodium falciparum infections in native Amazonian populations. Amer. J. trop. Med. Hyg., 66: 641-648, 2002.

3. ANDERSON, T.J.; HAUBOLD, B.; WILLIAMS, J.T. et al. - Microsatellite markers reveal a spectrum of population structures in the malaria parasite Plasmodium falciparum. Molec. Biol. Evol., 17: 1467-1482, 2000.

4. ANDERSON, T.J.; SU, X.Z.; BOCKARIE, M.; LAGOG, M. \& DAY, K.P. - Twelve microsatellite markers for characterization of Plasmodium falciparum from fingerprick blood samples. Parasitology, 119: 113-125, 1999.

5. ARIEY, F.; HOMMEL, D.; LE SCANF, C. et al. - Association of severe malaria with a specific Plasmodium falciparum genotype in French Guiana. J. infect. Dis., 184: 237-241, 2001.

6. BARUCH, D.I.; PASLOSKE, B.L.; SINGH, H.B. et al. - Cloning the P. falciparum gene encoding PfEMP1, a malarial variant antigen and adherence receptor on the surface of parasitized human erythrocytes. Cell, 82: 77-87, 1995.

7. BRUCE, M.C.; GALINSKI, M.R.; BARNWELL, J.W. et al. - Genetic diversity and dynamics of Plasmodium falciparum and $P$. vivax populations in multiply infected children with asymptomatic malaria infections in Papua New Guinea. Parasitology, 121: $257-272,2000$.

8. BUFFET, P.A.; GAMAIN, B.; SCHEIDIG, C. et al. - Plasmodium falciparum domain mediating adhesion to chondroitin sulfate A: a receptor for human placental infection. Proc. nat. Acad. Sci. (Wash.), 96: 12743-12748, 1999.

9. BULL, P.C.; LOWE, B.S.; KORTOK, M. et al. - Parasite antigens on the infected red cell surface are targets for naturally acquired immunity to malaria. Nature Med., 4: 358-360, 1998.

10. CHEN, Q.; FERNANDEZ, V.; SUNDSTRÖM, A. et al. - Developmental selection of var gene expression in Plasmodium falciparum. Nature (Lond.), 394: 392-395, 1998.

11. DUFFY, M.F.; BROWN, G.V.; BASUKI, W. et al. - Transcription of multiple var genes by individual, trophozoite-stage Plasmodium falciparum cells expressing a chondroitin sulphate A binding phenotype. Molec. Microbiol., 43: 1285-1293, 2002.

12. FOWLER, E.V.; PETERS, J.M.; GATTON, M.L.; CHEN, N. \& CHENG, Q. - Genetic diversity of the DBLalpha region in Plasmodium falciparum var genes among AsiaPacific isolates. Molec. Biochem. Parasit., 120: 117-126, 2002.

13. HERNANDEZ RIVAS, R.; MATTEI, D.; STERKERS, Y. et al. - Expressed var genes are found in Plasmodium falciparum subtelomeric regions. Molec. cell. Biol., 17: 604-611, 1997.

14. HORROCKS, P.; PINCHES, R.; CHRISTODOULOU, Z.; KYES, S.A. \& NEWBOLD, C.I. - Variable var transition rates underlie antigenic variation in malaria. Proc. nat. Acad. Sci. (Wash.), 101: 11129-11134, 2004.

15. KAESTLI, M.; CORTES, A.; LAGOG, M.; OTT, M. \& BECK, H.P. - Longitudinal assessment of Plasmodium falciparum var gene transcription in naturally infected asymptomatic children in Papua New Guinea. J. infect. Dis., 189: 1942-1951, 2004.

16. KIRCHGATTER, K. \& DEL PORTILLO, H.A. - Association of severe noncerebral Plasmodium falciparum malaria in Brazil with expressed PfEMP1 DBL1[alpha] sequences lacking cysteine residues. Molec. Med., 8: 16-23, 2002.

17. KYES, S.; TAYLOR, H.; CRAIG, A.; MARSH, K. \& NEWBOLD, C. - Genomic representation of var gene sequences in Plasmodium falciparum field isolates from different geographic regions. Molec. Biochem. Parasit., 87: 235-238, 1997. 


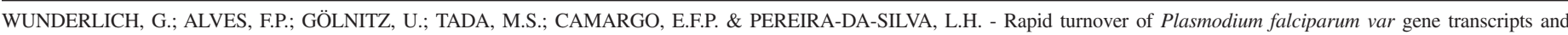
genotypes during natural non-symptomatic infections. Rev. Inst. Med. trop. S. Paulo, 47(4):195-201, 2005.

18. KYES, S.A.; CHRISTODOULOU, Z.; RAZA, A et al. - A well-conserved Plasmodium falciparum var gene shows an unusual stage-specific transcript pattern. Molec. Microbiol., 48: 1339-1348, 2003.

19. LEECH, J.H.; BARNWELL, J.W.; MILLER, L.H. \& HOWARD, R.J. - Identification of a strain-specific malarial antigen exposed on the surface of Plasmodium falciparuminfected erythrocytes. J. exp. Med., 159: 1567-1575, 1984.

20. NOVIYANTI, R.; BROWN, G.V.; WICKHAM, M.E. et al. - Multiple var gene transcripts are expressed in Plasmodium falciparum infected erythrocytes selected for adhesion. Molec. Biochem. Parasit., 114: 227-237, 2001.

21. OGUARIRI, R.M.; BORRMANN, S.; KLINKERT, M.-Q.; KREMSNER, P.G. \& KUN J.F. - High prevalence of human antibodies to recombinant Duffy binding-like protein alpha domains of the Plasmodium falciparum-infected erythrocyte membrane protein 1 in semi-immune adults compared to that in nonimmune children. Infect. Immun. 69: $7603-7609,2001$.

22. PAGET-McNiCOL, S.; GATTON, M.; HASTINGS, I. \& SAUL, A. - The Plasmodium falciparum var gene switching rate, switching mechanism and patterns of parasite recrudescence described by mathematical modelling. Parasitology, 124: 225-235, 2002

23. PETERS, J.; FOWLER, E.; GATTON, M. et al. - High diversity and rapid changeover of expressed var genes during the acute phase of Plasmodium falciparum infections in human volunteers. Proc. nat. Acad. Sci. (Wash.), 99: 10689-10694, 2002.

24. ROBERTS, D.J.; CRAIG, A.G.; BERENDT, A.R., et al. - Rapid switching to multiple antigenic and adhesive phenotypes in malaria. Nature (Lond.), 357: 689-692, 1992

25. SALANTI, A.; STAALSOE, T.; LAVSTSEN, T. et al. - Selective upregulation of a single distinctly structured var gene in chondroitin sulphate A-adhering Plasmodium falciparum involved in pregnancy-associated malaria. Molec. Microbiol., 49: 179191, 2003.
26. SAUL, A. - The role of variant surface antigens on malaria-infected red blood cells Parasit. today, 15: 455-457, 1999.

27. SCHERF, A.; HERNANDEZ-RIVAS, R.; BUFFET, P. et al. - Antigenic variation in malaria: in situ switching, relaxed and mutually exclusive transcription of var genes during intra-erythrocytic development in Plasmodium falciparum. Embo J., 17: 5418-5426, 1998

28. SCHLICHTHERLE, M.; WAHLGREN, M.; PERLMANN, H. \& SCHERF, A. - Methods in malaria research. Manassas, Virginia, MR4/ATCC, 2000.

29. SNOUNOU, G. - Detection and identification of the four malaria parasite species infecting humans by PCR amplification. Meth. Molec. Biol., 50: 263-291, 1996.

30. STAALSOE, T. \& HVIID, L. - The role of variant-specific immunity in asymptomatic malaria infections: maintaining a fine balance. Parasit. today, 14: 177-178, 1998

31. TAYLOR, H.M.; KYES, S.A.; HARRIS, D.; KRIEK, N. \& NEWBOLD, C.I. - A study of var gene transcription in vitro using universal var gene primers. Molec. Biochem. Parasit., 105: 13-23, 2000.

32. TRAGER, W. \& JENSEN, J.B. - Human malaria parasites in continuous culture. Science, 193: $673-675,1976$

33. VOGELSTEIN, B. \& GILLESPIE, D. - Preparative and analytical purification of DNA from agarose. Proc. nat. Acad. Sci. (Wash.), 76: 615-619, 1979.

34. WINTER, G.; CHEN, Q.; FLICK, K. et al. - The 3D7var5.2 (var COMMON) type var gene family is commonly expressed in non-placental Plasmodium falciparum malaria. Molec. Biochem. Parasit., 127: 179-191, 2003.

Received: 22 March 2005

Accepted: 20 May 2005 